\title{
Knowledge, attitudes and practices of malaria in Colombia
}

\author{
David A Forero', Pablo E Chaparro², Andres F Vallejo' ${ }^{1}$, Yoldy Benavides', Juan B Gutiérrez³, \\ Myriam Arévalo-Herrera ${ }^{4,5,6}$ and Sócrates Herrera ${ }^{4,6^{*}}$
}

\begin{abstract}
Background: Although Colombia has witnessed an important decrease in malaria transmission, the disease remains a public health problem with an estimated $\sim 10$ million people currently living in areas with malaria risk and $\sim 61,000$ cases reported in 2012. This study aimed to determine and compare the level of knowledge, attitudes and practices (KAP) about malaria in three endemic communities of Colombia to provide the knowledge framework for development of new intervention strategies for malaria elimination.
\end{abstract}

Methods: A cross-sectional KAP survey was conducted in the municipalities of Tierralta, Buenaventura and Tumaco, categorized according to high risk (HR) and moderate risk (MR) based on the annual parasite index (API). Surveys were managed using REDCap and analysed using MATLAB and GraphPad Prism.

Results: A total of 267 residents, mostly women (74\%) were surveyed. Although no differences were observed on the knowledge of classical malaria symptoms between HR and MR regions, significant differences were found in knowledge and attitudes about transmission mechanisms, anti-malarial use and malaria diagnosis. Most responders in both regions (93.5\% in MR, and 94.3\% in HR areas) indicated use of insecticide-treated nets (ITNs) to protect themselves from malaria, and $75.5 \%$ of responders in HR indicated they did nothing to prevent malaria transmission outdoors. Despite a high level of knowledge in the study regions, significant gaps persisted relating to practices. Self-medication and poor adherence to treatment, as well as lack of both indoor and outdoor vector control measures, were significantly associated with higher malaria risk.

Conclusions: Although significant efforts are currently being made by the Ministry of Health to use community education as one of the main components of the control strategy, these generic education programmes may not be applicable to all endemic regions of Colombia given the substantial geographic, ethnic and cultural diversity.

\section{Background}

Malaria causes over 207 million clinical cases and $\sim 627,000$ deaths worldwide every year representing an enormous global, social and economic burden [1]. Although, the American continent contributes a minor percentage of these cases, malaria is endemic in 21 countries of the continent with $\sim 469,000$ cases reported in 2012, most of them from Brazil (52\%) and Colombia (13\%) [1]. Several countries of the region, such as Argentina, Belize, Bolivia, Costa Rica, Ecuador, El Salvador, French Guiana, Guatemala, Honduras, Mexico, Nicaragua, Paraguay, and

\footnotetext{
*Correspondence: sherrera@inmuno.org

${ }^{4}$ Caucaseco Scientific Research Center, Cali, Colombia

${ }^{6}$ Latin American Center for Malaria Research, Cali, Colombia

Full list of author information is available at the end of the article
}

Suriname have experienced a drastic decrease in malaria case incidence $(>75 \%)$ during the last decade [1]. Even though Colombia has also witnessed an important decrease in transmission, malaria remains a public health problem with an unstable transmission pattern that in 2010 accounted for $\sim 117,000$ cases [2] and $\sim 61,000$ cases in 2012 [3]. An estimated $\sim 10$ million people currently live in areas with variable malaria risk, mainly distributed in the north-western part of the country (departments of Córdoba and Antioquia) and in the western region, along the Pacific coast, comprised of the departments of Chocó, Valle, Cauca and Nariño. In this most endemic area, $\sim 12.5 \%$ of the population live in high risk (HR) areas

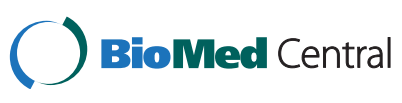

(c) 2014 Forero et al.; licensee BioMed Central Ltd. This is an Open Access article distributed under the terms of the Creative Commons Attribution License (http://creativecommons.org/licenses/by/4.0), which permits unrestricted use, distribution, and reproduction in any medium, provided the original work is properly credited. The Creative Commons Public Domain Dedication waiver (http://creativecommons.org/publicdomain/zero/1.0/) applies to the data made available in this article, unless otherwise stated. 
with annual parasite index (API) $\geq 10, \sim 20.0 \%$ in moderate risk (MR) areas with API values of 1 to 10 , and the remaining $(67.5 \%)$ in low transmission areas (API <1). In addition, there is an extraordinary geographic, ethnic and cultural diversity among these regions [4].

Although previous studies have indicated that malaria risk in both rural and urban endemic areas of Colombia is associated with factors such as age, number of people per household, occupation and level of education [5-8], regional differences in terms of transmission intensities and cultural background have not been determined.

Prevention and control activities developed by the National Malaria Control Programme (NMCP) of Colombia are mainly focused on early diagnosis and prompt treatment; distribution of long-lasting, insecticide-treated nets (LLINs); and education programmes. Despite these activities, the milestones proposed by the Ministry of Health $(\mathrm{MoH})$ for reducing morbidity by $70 \%$ and eliminating urban malaria transmission by 2021 [9] have not been reached completely due to factors such as presence of malaria in remote areas with limited access to health and education services, political instability and several other constraints.

Two of the study areas, Tierralta (HR) and Buenaventura (MR), are currently the subject of active control activities developed jointly between the NMCP and a project sponsored by the Global Fund for AIDS, Tuberculosis and Malaria (GFATM) where education is one of the major components. The ongoing education effort consists of distributing booklets, videos, shirts, school bags, and other materials targeting children; and games, murals, and advertisements that target adults.

Because malaria is associated with poverty [10], most endemic countries or regions within a country usually correspond to those communities with the lowest socioeconomic status. These are frequently found in regions where malaria control is logistically and economically more challenging due to the limited capacity of local and national governments to invest in health and infrastructure. In these areas, community participation in malaria control and elimination activities is essential to achieve success and sustainability. A community's commitment to participate in malaria prevention requires a minimal level of education in order to develop an adequate understanding of transmission, and thereby contribute to adapting attitudes towards malaria control/elimination [11-13].

In view of the limited knowledge, attitudes and practices (KAP) studies in Colombia $[7,8,14]$, and the growing national interest in strengthening malaria control activities [9], the purpose of this study was to determine and compare KAP about malaria in the communities of three municipalities of Colombia, and to provide the knowledge framework for development of new intervention strategies for malaria elimination.

\section{Methods}

\section{Study sites}

Sites selected for this survey included Tierralta, Buenaventura and Tumaco (Figure 1). Tierralta is a municipality located in the department of Cordoba in the northwestern part of the country, at $51 \mathrm{~m}$ above sea level (masl), $08^{\circ} 10^{\prime}$ $34^{\prime \prime}$ north latitude and $76^{\circ} 03^{\prime} 46^{\prime \prime}$ west longitude, covering an area of 5,079 sq $\mathrm{km}$, with an average temperature of $27.3^{\circ} \mathrm{C}$. Tierralta has a population of $\sim 90,000$ inhabitants, $44.4 \%$ of which live in rural areas, $55.6 \%$ in the urban area, with $\sim 2 \%$ indigenous population. The predominant malaria parasite species in the region is Plasmodium vivax (82.4\%) followed by Plasmodium falciparum $(17.4 \%)$, and $0.2 \%$ of mixed malaria infections. The sentinel sites selected in this region were Tuis Tuis and La Union.

Buenaventura is located on the Pacific coast in the department of Valle in the western part of Colombia, at 7 masl, covering an area of $6,078 \mathrm{sq} \mathrm{km}$, with an average temperature of $28^{\circ} \mathrm{C}$. The region consists of a tropical rainforest with a relative humidity of $85 \%$ and $\sim 8,000 \mathrm{~mm}$ of annual rainfall. Its population of $\sim 350,000$ inhabitants is predominantly Afro-descendant (72.4\%), with $13.4 \%$ considered white, $8.5 \%$ indigenous, and $5.7 \%$ mestizo. Malaria occurs throughout the year, with two small seasonal transmission peaks from April to May and September to October [15]. The predominant malaria parasite species in the region is $P$. vivax (85\%) followed by $P$. falciparum (15\%). The sentinel sites selected in this region were Punta Soldado, Zacarias and La Delfina.

Tumaco is located in the department of Nariño, in the south-western region of the country, near the border with Ecuador, at 2 masl, covering an area of 3,778 sq $\mathrm{km}$, with an average temperature of $28^{\circ} \mathrm{C}$. The population of Tumaco, estimated at 187,084 inhabitants, is composed mainly of Afro-descendants (88\%). Plasmodium falciparum has a prevalence of $79.2 \%$ and $20.8 \% P$. vivax. The sentinel sites selected in this region were Robles, Candelilla and Bucheli.

The population was divided into two groups according to the API recorded in the last five years (2008-2012), $\mathrm{HR}$ areas corresponded to API $\geq 10$, whereas $\mathrm{MR}$ were areas with $10>$ API $>1$. Based on these categories, Tierralta (Córdoba) with API of 44.0 cases/1,000 habitants was considered an HR area, whereas Buenaventura (Valle del Cauca) and Tumaco (Nariño), with API of 6.0 cases/ 1,000 habitants and 7.7 cases/1,000 habitants, respectively, were considered MR areas.

\section{Study design and ethical approval}

The study corresponded to a cross-sectional survey, conducted between October and December 2011 in eight sentinel sites selected based on API and socio-demographic characteristics. The study was developed in two steps: the 


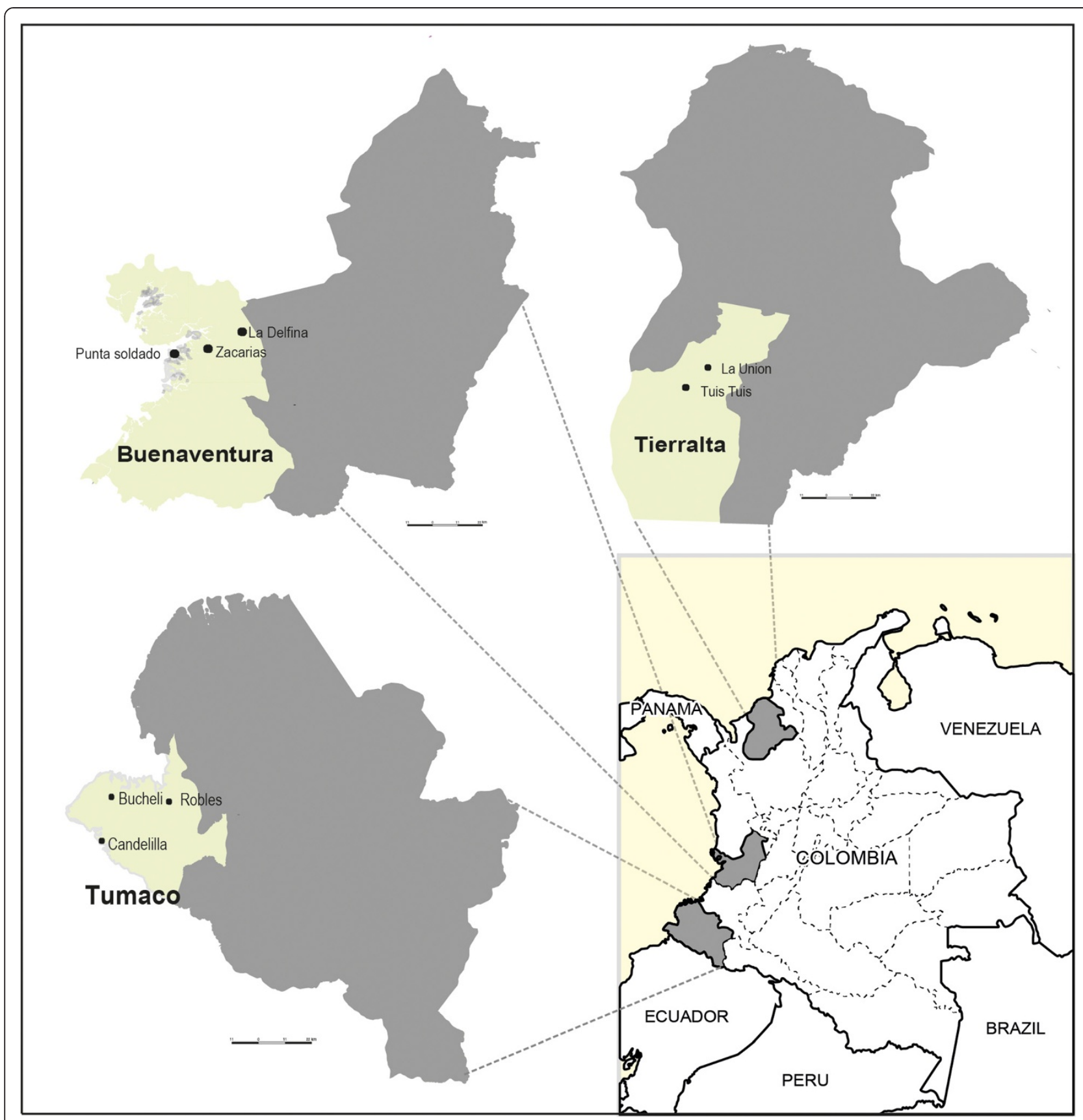

Figure 1 Study sites. Map of Colombia showing the location of the sentinel study sites. The insert depicts the location of the study areas within the country.

first, a door-to-door census of the entire population of each sentinel site; and the second, a survey using a structured questionnaire carried out by trained field workers. The survey was directed to heads of households in a subset of randomly selected houses. The same team of trained physicians accompanied the local teams to all eight sentinel sites. The trial was conducted according to Declaration of Helsinki principles, International Conference on Harmonization, ICH E-6 Guidelines for Good Clinical Practices and all pertinent Colombian regulations. The study protocol was approved by Institutional Review Boards (IRB) of the Malaria Vaccine and Drug Development Center-MVDC (CECIV,Cali) (Number: 009). Written informed consent (IC) was obtained from each volunteer at enrollment.

\section{KAP evaluation and socio-demographic assessment}

The questionnaire had a total of 41 questions divided as follows: 12 questions on knowledge of the malaria 
vector, symptoms, treatment, diagnosis, and prevention measures; ten questions on attitudes towards transmission, prevention and diagnosis; and, nine questions on practices such as the use of insecticide-treated nets (ITN), and thick blood smear (TBS) diagnosis and treatment. For assessment of socio-demographic characteristics, ten questions on public services, education level, ethnicity, and employment were included.

\section{Data analysis}

Data entry: information was captured in the field on paper-based case report forms (CRF). Data were digitized using REDCap (version 4.1) and imported into MATLAB (version 2011b) for analysis. The number of CRFs per location was: Buenaventura, 105; Tierralta, 53; Tumaco, 109. The MATLAB script used for analysis was provided in Additional file 1.

\section{Data quality assurance}

The data quality assurance (QA) procedure consisted of setting a quality control (QC) sample of size $q$ less than the total number $p$ of all CRFs for each location. Since during the QC procedure all errors found were corrected, it is possible to calculate the number of iterations of QC needed to bring the error below an acceptable threshold. During the first iteration of $\mathrm{QC}, e=\frac{\tilde{q}}{q}$ represents the percentage of error found during a QC procedure, where $\tilde{q}$ is the number of CRFs with at least one error. Assuming a uniform distribution of error, the percentage of total error after finding and correcting errors in the first QC sample of size $q$ is $T=\frac{e}{q}(p-q)$. After $n$ iterations of $\mathrm{QC}$, the percentage of total error is $T=\frac{e}{q}$ $(p-n q)$. Let $T_{a}$ represent now the target QA threshold of acceptable error. Then, the number $n$ of iterations of QC needed to bring down the error to acceptable levels is $n=\frac{p}{q}\left(1-\frac{T_{a}}{e}\right)$. The maximum permissible error $T_{a}$ for this study was established at $1 \%$. While this procedure might seem unnecessary for such a small sample, it lays the foundation for more comprehensive studies that will be conducted in the near future as a continuation of the present study.

Using descriptive statistics, the general characteristics of communities, families, and individuals admitted to the study were established. Measures of central tendency and dispersion were calculated for quantitative characteristics, whereas absolute frequencies as well as confidence intervals were used for qualitative characteristics.

For each question, association tests were performed using the Chi-square test with significant differences set at $\mathrm{p}$-value $<0.05$. Some questions in the CRFs were used to determine the correlation of malaria incidence and KAP. For the purpose of analysis, incidence was estimated taking into account the records of the NMCP, which were based on microscopic analyses of active and passive case detections.

\section{Results}

\section{Characteristics of respondents and housing}

A total of 267 houses inhabited by 1,170 residents were surveyed; 214 houses were located in MR, and 53 in HR. In MR areas (Tumaco and Buenaventura), 13.2\% of responders reported at least one malaria episode in the last year in the household, whereas in the HR area (Tierralta) this proportion was found to be $25.2 \%$. This information was used for association analysis.

The surveys were administered to heads of households, who in most cases were women $(\mathrm{MR}=75.7 \%$; $\mathrm{HR}=$ $67.9 \%)$. Most of the participants were housewives (MR = $56.5 \%$; $\mathrm{HR}=62.3 \%$; some were students or had other occupations (Table 1). A small proportion of responders (8.9\%) in MR had never attended school compared with

Table 1 Demographic characteristics of persons in selected households

\begin{tabular}{|c|c|c|c|c|c|}
\hline \multirow[b]{2}{*}{ Gender } & \multicolumn{2}{|c|}{$\frac{\text { Medium risk }}{(n=214)}$} & \multicolumn{2}{|c|}{$\frac{\text { High risk }}{(n=53)}$} & \multirow[b]{2}{*}{$\mathrm{p}$-value } \\
\hline & $\mathbf{n}$ & $\%$ & $\mathrm{n}$ & $\%$ & \\
\hline Female & 162 & 75.7 & 36 & 67.9 & 0.247 \\
\hline Male & 52 & 24.3 & 17 & 32.1 & \\
\hline \multicolumn{6}{|l|}{ Occupation } \\
\hline Labourer & 10 & 4.7 & 14 & 26.4 & 0.000 \\
\hline Farmer & 19 & 8.9 & 1 & 1.9 & 0.083 \\
\hline Housewife & 121 & 56.5 & 33 & 62.3 & 0.450 \\
\hline Student & 13 & 6.1 & 0 & 0.0 & 0.065 \\
\hline \multicolumn{6}{|l|}{ House type } \\
\hline Brick & 110 & 51.4 & 9 & 17.0 & 0.000 \\
\hline Wooden hut & 75 & 35.0 & 1 & 1.9 & 0.000 \\
\hline Shacks & 25 & 11.7 & 43 & 81.1 & 0.000 \\
\hline \multicolumn{6}{|c|}{ Where is the sanitary service? } \\
\hline Inside the house & 93 & 43.5 & 3 & 5.7 & 0.000 \\
\hline Outside the house & 119 & 55.6 & 50 & 94.3 & \\
\hline \multicolumn{6}{|l|}{ Distance source of water } \\
\hline Inside House & 130 & 60.7 & 1 & 1.9 & 0.000 \\
\hline Less than $20 \mathrm{~m}$ & 26 & 12.1 & 15 & 28.3 & 0.003 \\
\hline Between 50 and $100 \mathrm{~m}$ & 13 & 6.1 & 13 & 24.5 & 0.000 \\
\hline More than $100 \mathrm{~m}$ & 5 & 2.3 & 23 & 43.4 & 0.000 \\
\hline \multicolumn{6}{|l|}{ Source of water } \\
\hline Aqueduct & 133 & 62.1 & 1 & 1.9 & 0.000 \\
\hline Well & 23 & 10.7 & 19 & 35.8 & 0.000 \\
\hline River & 5 & 2.3 & 28 & 52.8 & 0.000 \\
\hline Rainwater & 47 & 22.0 & 5 & 9.4 & 0.039 \\
\hline
\end{tabular}


$17.0 \%$ in HR; $47.7 \%$ of the participants from MR, and $64.2 \%$ from HR had at least a primary education.

A higher percentage of the population from MR areas (37.4\%) than HR areas (9.4\%) had some level of secondary education; $4.2 \%$ in MR areas, and $0 \%$ in $\mathrm{HR}$ areas had technical education (Figure 2). Houses in MR areas were constructed of brick (51.4\%) and wood (35.0\%); 81.3\% had electricity; and $62.1 \%$ had a drinking water supply. In contrast, the houses in HR were built of brick (17.0\%) and wood (1.9\%); 100\% had electricity; and only $1.9 \%$ of houses had an aqueduct.

\section{Knowledge}

Of the total responders, $86.9 \%$ in MR areas and $79.2 \%$ in $\mathrm{HR}$ areas knew that malaria is acquired by the bite of an infected mosquito and a small proportion $(\mathrm{HR}=5.7 \%)$ knew that malaria could be transmitted through blood transfusion. In both groups, fever, headache and chills were identified as the first symptoms detected in a person with malaria. Other recognized symptoms were myalgia and arthralgia, weakness and sweating; no significant differences were found between the two groups. Additionally, $\sim 90 \%$ in both groups reported to have visited a local clinic with a microscopist or other health officer when they had malaria symptoms (Table 2).

Responders in both $\mathrm{MR}$ and $\mathrm{HR}$ areas had variable knowledge on malaria preventive measures. Most participants knew about tablets that could cure malaria (MR $=89.3 \%$; $\mathrm{HR}=92.5 \%$ ); however a small proportion $(2.8 \%)$ of responders from MR areas believed that home treatments were more suitable to cure the disease, while in HR areas nobody believed this; and $1.9 \%$ indicated that malaria treatment was not necessary. With respect to completing drug treatment in MR areas, $82.2 \%$ knew that interrupting malaria treatment may lead to death, whereas in HR areas only $15.1 \%$ knew this ( $p=0.000)$. In both areas, the community health promoter was identified by responders as responsible for malaria control $(\mathrm{MR}=48.1 \% ; \mathrm{HR}=37.3 \%)(\mathrm{p}=0.174)$. For $66.4 \%$ of responders from MR areas, the main source of knowledge on malaria was friends, compared with $34.0 \%$ in HR areas. In contrast, in HR areas it was found that family played an important role (52.8\%) as a source of knowledge on malaria, while in MR areas this was less prevalent $(29.4 \%)$. This factor was significantly different between the responders of the two areas $(p=0.001)$. Surprisingly, few responders felt that the government or health promoters had taught them about malaria.

With regard to intervention measures for indoor prevention and vector control, a higher percentage of responders from HR areas (86.8\%) mentioned the use of ITNs compared with responders from MR areas (68.2\%). Despite $\mathrm{MoH}$ recommend to avoid indoor residual spraying (IRS) in areas with coverage of ITN, in MR areas, $40.2 \%$ of responders knew that indoor residual spraying (IRS) was a prevention measure compared with only $3.8 \%$ in HR areas $(\mathrm{p}<0.000)$. Regarding outdoor vector control measures, a high percentage of people in MR areas knew that the presence of long grass (34.6\%) and standing water (39.7\%) should be avoided. Use of insecticide spraying $(28.5 \%)$ in order to significantly reduce mosquito populations was recognized, whereas in HR areas knowledge of these three features was minimal (5.7, 3.8 and $3.8 \%$, respectively). This knowledge was significantly different between the responders from the two areas. In HR areas $62.3 \%$ did not respond or did not know the availability of outdoor malaria prevention measures.

\section{Attitudes}

In $\mathrm{MR}$ areas $45.8 \%$ of responders believed that getting malaria was normal, whereas only $11.3 \%$ in $\mathrm{HR}$ areas

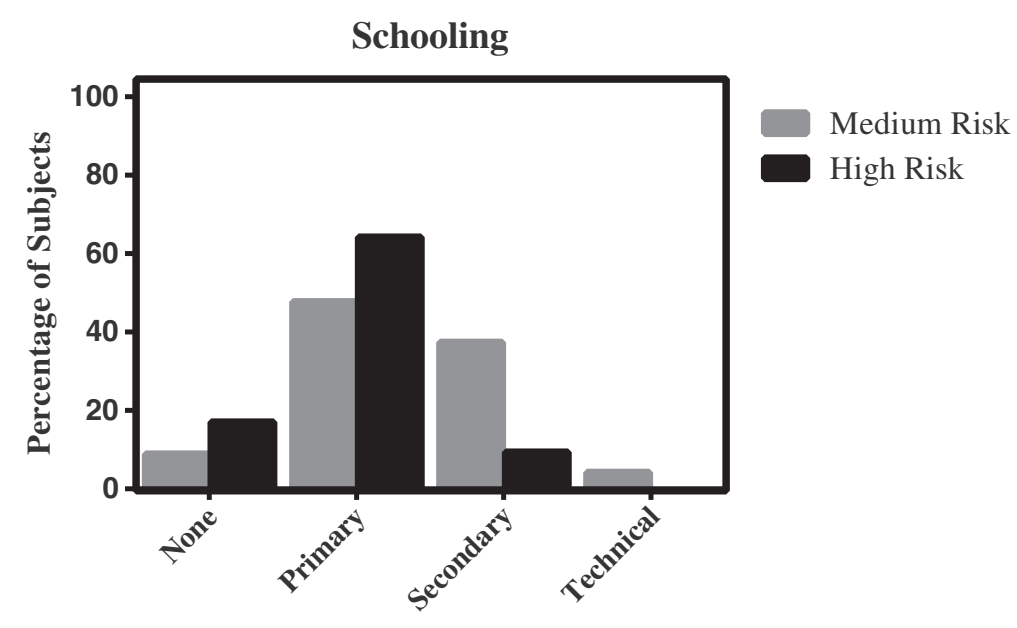

Figure 2 Education. 
Table 2 Malaria knowledge of participants in the selected study households

\begin{tabular}{|c|c|c|c|c|c|}
\hline & & & & & \\
\hline & & & & & \\
\hline & $\mathbf{n}$ & $\%$ & $\mathrm{n}$ & $\%$ & p-value \\
\hline Yes/No questions & & & & & \\
\hline Does the person know how malaria is transmitted? (Yes) & 186 & 86.9 & 42 & 79.2 & 0.157 \\
\hline Can malaria be transmitted by blood transfusion? (Yes) & 0 & 0.0 & 3 & 5.7 & - \\
\hline Is it necessary to go to the microscopist? (Yes) & 192 & 89.7 & 49 & 92.5 & 0.548 \\
\hline Can malaria be cured with tablets? (Yes) & 191 & 89.3 & 49 & 92.5 & 0.489 \\
\hline Multiple choice questions & & & & & \\
\hline What are the Malaria symptoms? & & & & & \\
\hline Fever & 113 & 52.8 & 27 & 50.9 & 0.808 \\
\hline Headache & 38 & 17.8 & 7 & 13.2 & 0.428 \\
\hline Chills & 32 & 15.0 & 11 & 20.8 & 0.304 \\
\hline What happens if a person does not complete the treatm & & & & & \\
\hline Nothing & 8 & 3.7 & 13 & 24.5 & 0.000 \\
\hline Can die & 176 & 82.2 & 8 & 15.1 & 0.000 \\
\hline Who taught you what you know about malaria? & & & & & \\
\hline Friends & 142 & 66.4 & 18 & 34.0 & 0.000 \\
\hline Family & 63 & 29.4 & 28 & 52.8 & 0.001 \\
\hline School & 9 & 4.2 & 6 & 11.3 & 0.044 \\
\hline Responsible for malaria control & & & & & \\
\hline Government & 62 & 29.0 & 8 & 15.1 & 0.040 \\
\hline Health promoter & 103 & 48.1 & 20 & 37.3 & 0.174 \\
\hline What can be done inside the house to prevent malaria? & & & & & \\
\hline ITN & 146 & 68.2 & 46 & 86.8 & 0.007 \\
\hline IRS & 86 & 40.2 & 2 & 3.8 & 0.000 \\
\hline Cannot do anything & 1 & 0.5 & 2 & 3.8 & 0.041 \\
\hline What can be done outside the house to prevent malaria? & & & & & \\
\hline Avoid weeds, cut grass & 74 & 34.6 & 3 & 5.7 & 0.000 \\
\hline Avoid standing water & 85 & 39.7 & 2 & 3.8 & 0.000 \\
\hline Insecticide spraying & 61 & 28.5 & 2 & 3.8 & 0.000 \\
\hline Cannot do anything & 5 & 2.3 & 11 & 20.8 & 0.000 \\
\hline Not known - No answers & 22 & 10.3 & 33 & 62.3 & 0.000 \\
\hline
\end{tabular}

believed it was normal (Table 3) with significant differences $(\mathrm{p}=0.000)$. In MR and HR areas, 89.3 and $77.4 \%$ of responders, respectively, had used anti-malarial drugs to treat malaria symptoms and as a useful means to kill the parasite $(\mathrm{p}=0.021)$. Regarding diagnosis, $93.5 \%$ in MR areas and $71.7 \%$ in HR areas thought that the TBS was necessary to determine if a person had malaria $(\mathrm{p}=0.000)$, additionally, $86.0 \%$ of responders from MR areas and 47.2\% from HR areas considered that prescribed antimalarials must be continued even after feeling better ( $\mathrm{p}=0.000) ; 29.4 \%$ in $\mathrm{MR}$ areas compared to $52.8 \%$ in HR areas admitted having purchased tablets without medical prescription $(\mathrm{p}=0.001)$. Moreover, $9.8 \%$ of responders in MR areas compared with $22.6 \%$ in HR areas responded as if that malaria is a disease transmitted from a sick person to a healthy one through physical contact $(\mathrm{p}=0.011)$.

\section{Practices}

To control indoor malaria transmission, most responders in both regions $(\mathrm{MR}=93.5 \%$; $\mathrm{HR}=94.3 \%)$ indicated the use of INT for malaria protection; further, $26.2 \%$ of responders from MR areas, but none from HR areas, reported using home spray (Figure 3). Regarding outdoor mosquito control, $35.5 \%$ of $\mathrm{MR}$ inhabitants regularly monitored the presence of standing water in their neighbourhoods compared to $1.9 \%$ in $\mathrm{HR}$ areas. 
Table 3 Attitudes about malaria

\begin{tabular}{|c|c|c|c|c|c|}
\hline \multirow[b]{3}{*}{ Responded affirmatively } & \multirow{2}{*}{\multicolumn{2}{|c|}{$\begin{array}{c}\text { Medium risk } \\
(n=214)\end{array}$}} & \multirow{2}{*}{\multicolumn{2}{|c|}{$\begin{array}{c}\text { High risk } \\
(n=53)\end{array}$}} & \multirow[b]{3}{*}{ p-value } \\
\hline & & & & & \\
\hline & n & $\%$ & $\mathrm{n}$ & $\%$ & \\
\hline Is getting malaria normal? & 98 & 45.8 & 6 & 11.3 & 0.000 \\
\hline Does standing water facilitate transmission? & 179 & 83.6 & 45 & 84.9 & 0.823 \\
\hline Can tablets cure malaria? & 191 & 89.3 & 41 & 77.4 & 0.022 \\
\hline Is the blood smear necessary? & 200 & 93.5 & 38 & 71.7 & 0.000 \\
\hline Is it needed to finish the treatment? & 184 & 86.0 & 25 & 47.2 & 0.000 \\
\hline Have you had malaria more than once? & 195 & 91.1 & 45 & 84.9 & 0.179 \\
\hline Have you bought tablets without a prescription? & 63 & 29.4 & 28 & 52.8 & 0.001 \\
\hline Can physical contact transmit malaria? & 21 & 9.8 & 12 & 22.6 & 0.011 \\
\hline Is it annoying to use bed nets? & 39 & 18.2 & 14 & 26.4 & 0.181 \\
\hline Does the presence of mosquitoes bother you? & 204 & 95.3 & 47 & 88.7 & 0.068 \\
\hline
\end{tabular}

Additionally, 45.3\% of MR participants used insecticide home-spray compared with $1.9 \%$ in $\mathrm{HR}$ areas. In HR areas $75.5 \%$ of responders did nothing outside the home to prevent malaria. Regarding malaria diagnosis, at the onset of malaria symptoms $88.9 \%$ and $83 \%$ of responders in MR and HR areas, respectively, initially attended a local clinic with either a microscopist, physician or health promoter to perform the TBS. In MR areas, $29.0 \%$ of respondents consulted first with health services and $17.8 \%$ with the health promoter, whereas in HR areas these two alternatives were not consulted. About $75.7 \%$ and $98.1 \%$ of responders from MR and HR areas, respectively, reported that the place of malaria diagnosis was located less than one hour away from their households. In MR areas, $60.7 \%$ travelled to the point of diagnosis by foot, compared with $98.1 \%$ in HR areas; in MR areas $21.5 \%$ used a motor vehicle. The practices mentioned above were significantly different between the responders of the two areas $(\mathrm{p}<0.050)$ (Table 4).

\section{Association of malaria KAP and malaria incidence}

Despite knowing that the use of an ITN prevents malaria transmission, no significant differences were found between this knowledge and having suffered malaria in the last year $(p>0.050)$. Likewise, no correlation was found between malaria prevalence in the three municipalities and the knowledge about use of IRS to reduce malaria transmission. This knowledge was related to malaria prevalence in MR areas $(\mathrm{p}<0.050)$.

A high proportion of responders in both areas $(93.5 \%$ in MR, and $94.3 \%$ in HR areas) reported using ITNs because they knew it prevented malaria transmission,

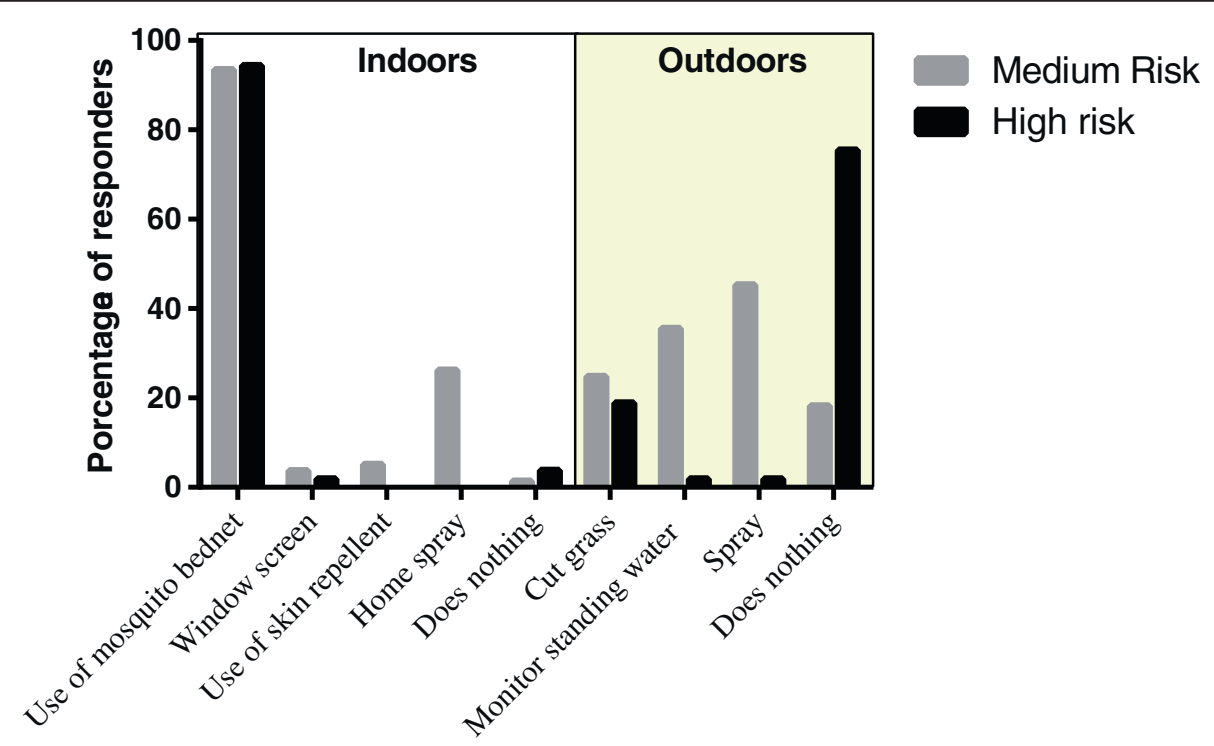

Figure 3 Practices to prevent malaria. 


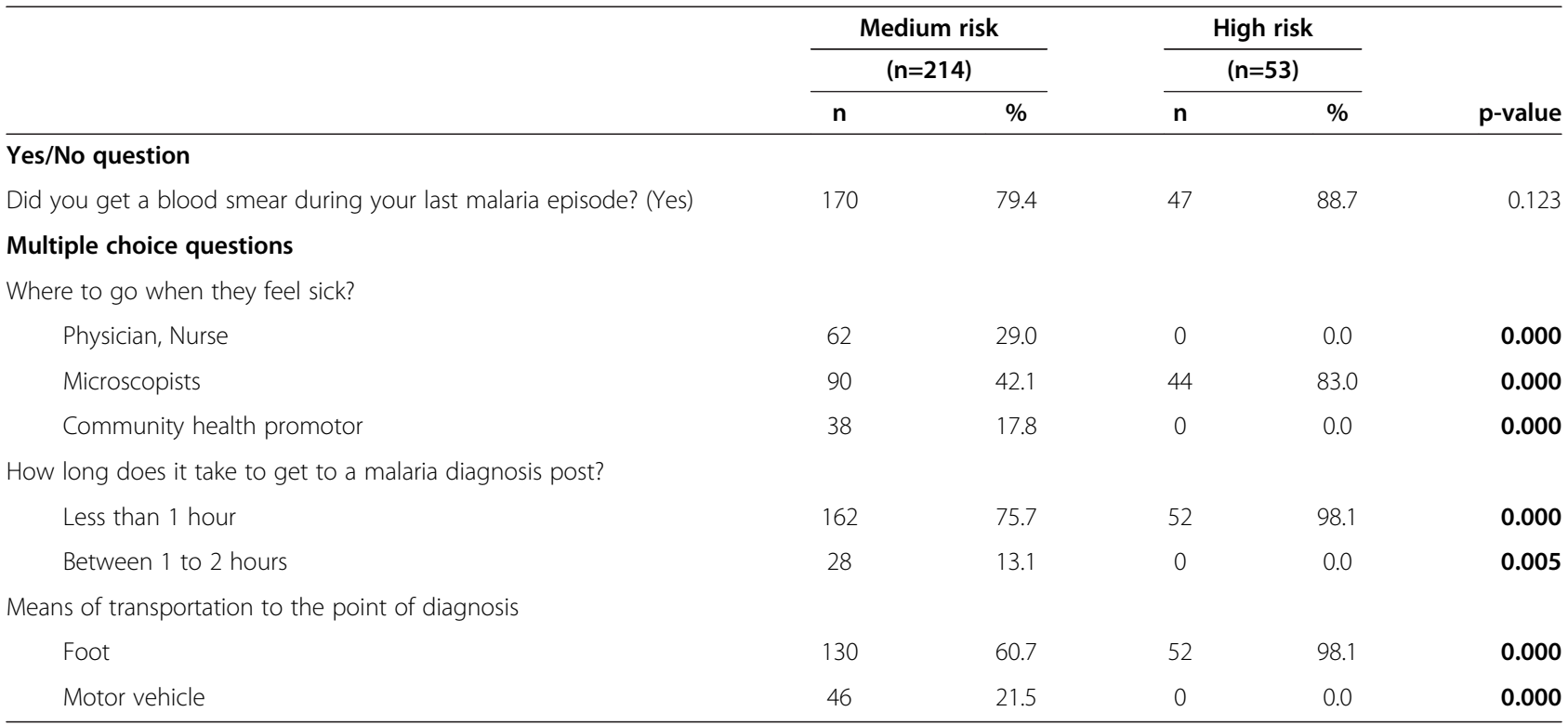

however no significant differences were found between the use of ITNs and having malaria. Having ponds or standing water around the house was significantly associated with having suffered malaria over the last year $(\mathrm{p}<0.050)$ in $\mathrm{MR}$ areas but not in HR areas: $36.4 \%$ of responders in MR areas and $4.8 \%$ in HR areas knew that avoiding standing water could reduce malaria transmission.

\section{Discussion}

This study was conducted to identify the KAP related to malaria in endemic areas of Colombia. Significant differences in the level of education in the two group categories were found. HR areas showed a higher proportion of illiteracy than in MR areas $(p=0.000)$. Furthermore, the level of primary education was higher in HR areas (64.2\%) than in MR (47.7\%) ( $\mathrm{p}=0.031)$; however, the overall education level was higher in MR areas. Correlation between the level of formal education and malaria risk was not found, probably due to the overall high knowledge level in both areas. Most people in both regions stated that they had learned about malaria from their families (33.6\%) or friends (59.0\%). Previous reports indicating that the level of literacy has a direct correlation with best malaria practices $[16,17]$, and that increasing the literacy level would serve as a protective factor against malaria morbidity $[18,19]$. Previous studies have also indicated that malaria knowledge was only marginally better in areas with higher education levels [20].

Similar to other reports [21-27], in this study, knowledge about malaria transmission mechanism was high. About $85 \%$ of the total responders knew that the bite of infected mosquito transmits the parasite to humans, and this could explain the high percentage of responders who knew about the benefits of ITN use; most of the study population $(>90 \%)$ used an ITN. This extended use of ITNs appears to be a result of the aggressive distribution of ITNs by the joint NMCP and GFATM malaria control programmes.

Other studies carried out in Latin American and Caribbean countries have investigated knowledge of the role of mosquitoes in malaria transmission. In a previous study in Haiti, despite the high level of knowledge about the role of mosquitoes in malaria transmission (61.8\%), poor ownership and use of ITNs was observed; no significant association was found between education and correct knowledge [13]. Likewise in Honduras, most participants in a KAP survey demonstrated general awareness of malaria and it transmission, but the study did not analyze the relationship between education level, malaria knowledge and disease prevalence [28]. In contrast in a study carried out in Mexico, malaria knowledge was poor; only $48 \%$ of the population associated malaria with mosquito bites, $99 \%$ of villagers had ITNs and $75.7 \%$ used them all year round [20]. In that study, the perceived benefit of IRS was associated with reduction in mosquitoes and other insects and pests, but only $3 \%$ associated it directly with prevention of malaria transmission. In Venezuela, $68.3 \%$ associated malaria with mosquito bites, however a high percentage (86.2\%) of respondents refused to use ITNs [29]. However, these studies showed an overall perspective and do not establish regional differences.

About half of the population interviewed in the present study identified fever as a major malaria symptom, results that are consistent with other studies [21,22,30-34]. For most of the population (89\%), fever 
with other classical malaria symptoms was an indication to visit a local clinic with a microscopist or other health officer. This was consistent with studies where communities with a good knowledge of the cause and manifestations of the disease seek early treatment $[21,30]$, yet it is in contrast with others where $>40 \%$ of responders delayed seeking malaria treatment $[22,35]$. In this context, it was surprising that about half of the responders in HR areas reported buying medicine without prescription, although this attitude was less prevalent $(\sim 30 \%)$ in MR areas. As reported in other studies, self-medication leads to late consultation, disease complications and possible emergence of drug resistance [36-42]. In the Mexican study, $>40 \%$ of villagers were reported to self-medicate when a family member experienced a fever episode [20].

Another relevant finding was that people from Buenaventura and Tumaco, both MR areas, had greater knowledge and better practices against the disease, probably due to permanent malaria education programmes. Tumaco was the subject of previous interventions by a GFATM for malaria control in the borders of Peru, Ecuador, Colombia, and Venezuela. This appears to be in agreement with the finding that knowledge about IRS was significantly higher in the MR area than in HR area (40.2 vs $3.8 \%, \mathrm{p}=0.000$ ), although overall results here are lower than those reported in a previous study carried out in Iran (64.6\%) [17]. However research in Zimbabwe showed a significant relationship between malaria knowledge and the use of preventive measures in the house. The level of understanding of IRS was directly correlated to compliance with having the house fumigated [43].

The limitations of this study are associated with the design of data collection procedures. The cross-sectional design provides information about a particular point in time, but it is unable to determine rates of change or stochastic variation. In addition, the data were collected from households only; some information was not confirmed, for example, that related to ITN use.

\section{Conclusion}

Despite high levels of knowledge in both regions, significant gaps relating to practices persist. There were significant differences in attitudes about buying medicine without a prescription, adherence to treatment and practices in both indoor and outdoor vector control prevention measures between respondents living in MR and HR areas. This study contrasts geographical regions of Colombia in their KAP on malaria and presents evidence that point to the need to develop educational programmes specific to each region based on the specific gaps found in this study. Education, control and elimination malaria programmes must take into account local characteristics in terms of the variables measured in this study for analysis, reporting and planning.
Finally, it is evident that communities in high and moderate transmission settings of Colombia are aware about transmission, symptoms, diagnosis and prevention of malaria. Nevertheless, Ministry of Health programmes must be able to correct misconceptions about malaria diagnosis and treatment as well as knowledge about mosquito control with focused health education initiatives.

\section{Additional file}

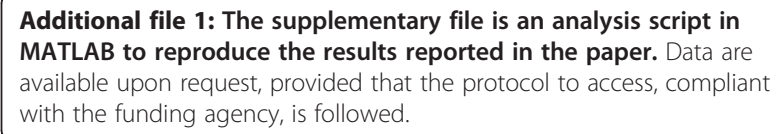

Competing interests

The authors declare that they have no competing interests.

\section{Authors' contributions}

SHV and MAR conceived and designed the study; PC, SH, MAR, AV, DF, and $J G$ wrote the manuscript; YB and JG conducted data management and data analysis. All authors read and approved the final manuscript.

\section{Acknowledgements}

We thank the endemic communities of Tierralta, Tumaco and Buenaventura for kindly participating in this study. We also thank Juan Pablo Quintero for the KAP survey design. This work was supported by the NIAID/ICEMR (research grant U19AI089702), Colciencias (research grant 360-2011 and 719-2013) and the Presidential Agency for International Cooperation of Colombia (APC grant 45-2013).

\section{Author details}

${ }^{1}$ Malaria Vaccine and Drug Development Center, Cali, Colombia. ${ }^{2}$ National Institute of Health of Colombia, Bogotá, Colombia. ${ }^{3}$ Institute of Bioinformatics \& Department of Mathematics, University of Georgia, Athens, GA, USA.

${ }^{4}$ Caucaseco Scientific Research Center, Cali, Colombia. ${ }^{5}$ School of Health, Universidad del Valle, Cali, Colombia. ' $L a t i n$ American Center for Malaria Research, Cali, Colombia.

Received: 12 February 2014 Accepted: 22 April 2014 Published: 1 May 2014

\section{References}

1. World malaria report 2013. [Available at: http://www.who.int/malaria/media/ world_malaria_report_2013/en/index.html]

2. Chaparro P, Padilla J, Vallejo AF, Herrera S: Characterization of a malaria outbreak in Colombia in 2010. Malar J 2013, 12:330.

3. Instituto Nacional de Salud: Boletín epidemiológico No 50 de la malaria en Colombia. Bogotá: Grupo Sivigila; 2012.

4. Escobar A: Política cultural y biodiversidad: Estado, capital y movimientos sociales en el pacífico colombiano. In Antropología en la Modernidad. Bogotá: Instituto Colombiano de Antropología; 1997:173-206.

5. Mendez F, Carrasquilla G, Munoz A: Risk factors associated with malaria infection in an urban setting. Trans R Soc Trop Med Hyg 2000, 94:367-371.

6. Balderrama F, Santander A: Riesgo de infección extradomiciliaria de la malaria en diferentes ámbitos ecológicos ocupacionales en bajo calima, Buenaventura, Colombia. University of Valle: MSc Thesis; 1985.

7. Nieto T, Mendez F, Carrasquilla G: Knowledge, beliefs and practices relevant for malaria control in an endemic urban area of the Colombian Pacific. Soc Sci Med 1999, 49:601-609.

8. Pineda F, Agudelo CA: Percepciones, actitudes y prácticas en malaria en el Amazonas Colombiano. Rev Salud Publica (Bogota) 2005, 7:339-348.

9. Estrategia de gestión integrada para la promoción, prevención y control de las enfermedades transmitidas por vectores en Colombia, 2012 - 2021. [http:// www.proyectomalariacolombia.co/files/msps/EGIETVNacionalversion 26demarzode2013.pdf] 
10. Worrall E, Basu S, Hanson K: Is malaria a disease of poverty? A review of the literature. Trop Med Int Health 2005, 10:1047-1059.

11. Kroeger A, Meyer R, Mancheno M, Gonzalez M, Pesse K: Operational aspects of bednet impregnation for community-based malaria control in Nicaragua, Ecuador, Peru and Colombia. Trop Med Int Health 1997, 2:589-602.

12. Klein RE, Weller SC, Zeissig R, Richards FO, Ruebush TK: Knowledge, beliefs, and practices in relation to malaria transmission and vector control in Guatemala. Am J Trop Med Hyg 1995, 52:383-388.

13. Keating J, Eisele TP, Bennett A, Johnson D, Macintyre K: A description of malaria-related knowledge, perceptions, and practices in the Artibonite Valley of Haiti: implications for malaria control. Am J Trop Med Hyg 2008, 78:262-269.

14. Pérez L, Suárez M, Murcia L, De la Hoz F, Olanos VA, Brochero H, Toro P: La malaria en el Amazonas: conocimientos, prácticas, prevalencia de parasitemia y evaluación entomológica en mayo de 1997. Biomedica 1999, 19:93-102.

15. Gautret P, Barreto M, Méndez F, Zorrilla G, Carrasquilla G: High prevalence of malaria in a village of the Colombian Pacific coast. Mem Inst Oswaldo Cruz 1995, 90:559-560.

16. Mazigo HD, Obasy E, Mauka W, Manyiri P, Zinga M, Kweka EJ, Mnyone LL, Heukelbach J: Knowledge, attitudes, and practices about malaria and its control in rural northwest Tanzania. Malar Res Treat 2010, 2010:794261.

17. Hanafi-Bojd A, Vatandoost H, Oshaghi M, Eshraghian M, Haghdoost A, Abedi F, Zamani G, Sedaghat M, Rashidian A, Madani A: Knowledge, attitudes and practices regarding malaria control in an endemic area of southern Iran. Southeast Asian J Trop Med Public Health 2011, 42:491.

18. Koram K, Bennett S, Adiamah J, Greenwood B: Socio-economic determinants are not major risk factors for severe malaria in Gambian children. Trans R Soc Trop Med Hyg 1995, 89:151-154.

19. Asl HM, Motabar M, Zamani G, Naserinejad D, Vatandoost H: A Casecontrol Study of Determinative Factors on Malaria Morbidity in Minab, Jask and Roodan Counties, in Hormozgan Province, Southern Iran, 2001. Iran J Public Health 2003, 32:14-18.

20. Rodriguez AD, Penilla RP, Henry-Rodriguez M, Hemingway J: Francisco Betanzos A, Hernandez-Avila JE: Knowledge and beliefs about malaria transmission and practices for vector control in southern Mexico. Salud Publica Mex 2003, 45:110-116.

21. Hlongwana KW, Mabaso ML, Kunene S, Govender D, Maharaj R: Community knowledge, attitudes and practices (KAP) on malaria in Swaziland: a country earmarked for malaria elimination. Malar J 2009, 8:29-37.

22. Saeed I, Ahmed E: Determinants of acquiring malaria among displaced people in Khartoum state, Sudan. East Mediterr Health J 2003, 9:581-592.

23. Govere J, Durrheim D, La Grange K, Mabuza A, Booman M: Community knowledge and perceptions about malaria and practices influencing malaria control in Mpumalanga Province, South Africa. S Afr Med J 2000 90:611-616.

24. Karanja D, Alaii J, Abok K, Adungo N, Githeko A, Seroney I, Vulule J, Odada $\mathrm{P}$, Oloo J: Knowledge and attitudes to malaria control and acceptability of permethrin impregnated sisal curtains. East Afr Med J 1999, 76:42-46.

25. Ahmed SM, Haque R, Haque U, Hossain A: Knowledge on the transmission, prevention and treatment of malaria among two endemic populations of Bangladesh and their health-seeking behaviour. Malar J 2009, 8:173.

26. De La Cruz N, Crookston B, Dearden K, Gray B, Ivins N, Alder S, Davis R: Who sleeps under bednets in Ghana? A doer/non-doer analysis of malaria prevention behaviours. Malar J 2006, 5:61.

27. Adam I, Salih A, Khamis AH, Malik EM: Perceptions of the causes of malaria and of its complications, treatment and prevention among midwives and pregnant women of Eastern Sudan. J Public Health 2008, 16:129-132.

28. Bell CE, Slutsker L, Beach RF, Foster SO, Jimenez G, Sarmiento ME: Malaria control in the municipality of San Esteban, Honduras. Rev Panam Salud Publica 2009, 25:213-217.

29. Sojo-Milano M, Cáceres JL, Sojo-Milano E, Rondón L, González C, Rubio N: Conocimientos, prácticas y percepciones sobre malaria en la parroquia Yaguaraparo, estado Sucre, Venezuela, 2004. Bol Malariología Salud Ambiental 2008, 48:61-71.

30. Faye O, Lo M, Diop B, Gaye O, Bah I, Dieng T, Dieng Y, N'Dir O, Diallo S: [Knowledge and treatment of malaria in rural Senegal](in French). Méd Trop (Marseilles) 1997, 57:161.
31. Hla-Shein T-T-S, Soe-Soez T-A, Ne-Winz K-S-A, Yangar M: The level of knowledge, attitude and practice in relation to malaria in Oo-do village, Myanmar. Age 1998, 18:42

32. Dunyo SK, Afari EA, Koram KA, Ahorlu CK, Abubakar I, Nkrumah FK: Health centre versus home presumptive diagnosis of malaria in southern Ghana: implications for home-based care policy. Trans $R$ Soc Trop Med Hyg 2000, 94:285-288.

33. Booth CM, MacLean JD: Knowledge, treatment-seeking, and socioeconomic impact of malaria on the Essequibo Coast of Guyana. Mcgill J Med 2001, 6:17-25.

34. Kamugisha M, Maxwell C, Curtis C: Characteristics of malaria among children living in lowland and highlands of Muheza Dirtrict, north-east Tanzania. Tanzan J Health Res 2005, 7:67-72.

35. McCombie S: Treatment seeking for malaria: a review of recent research. Soc Sci Med 1996, 43:933-945.

36. Yeneneh H, Gyorkos TW, Joseph L, Pickering J, Tedla S: Antimalarial drug utilization by women in Ethiopia: a knowledge-attitudes-practice study. Bull World Health Organ 1993, 71:763.

37. Ndyomugyenyi R, Magnussen P, Clarke S: Malaria treatment-seeking behaviour and drug prescription practices in an area of low transmission in Uganda: implications for prevention and control. Trans R Soc Trop Med Hyg 2007, 101:209-215.

38. Nuwaha F: People's perception of malaria in Mbarara, Uganda. Trop Med Int Health 2002, 7:462-470.

39. Malik EM, Hanafi K, Ali SH, Ahmed ES, Mohamed KA: Treatment-seeking behaviour for malaria in children under five years of age: implication for home management in rural areas with high seasonal transmission in Sudan. Malar J 2006, 5:60.

40. Nyamongo I: Health care switching behaviour of malaria patients in a Kenyan rural community. Soc Sci Med 2002, 54:377-386.

41. Comoro C, Nsimba S, Warsame M, Tomson G: Local understanding, perceptions and reported practices of mothers/guardians and health workers on childhood malaria in a Tanzanian district-implications for malaria control. Acta Trop 2003, 87:305-313.

42. Tyagi $P$, Roy A, Malhotra M: Knowledge, awareness and practices towards malaria in communities of rural, semi-rural and bordering areas of east Delhi (India). J Vector Borne Dis 2005, 42:30.

43. Vundule C, Mharakurwa S: Knowledge, practices, and perceptions about malaria in rural communities of Zimbabwe: relevance to malaria control. Bull World Health Organ 1996, 74:55.

doi:10.1186/1475-2875-13-165

Cite this article as: Forero et al:: Knowledge, attitudes and practices of malaria in Colombia. Malaria Journal 2014 13:165.

\section{Submit your next manuscript to BioMed Central and take full advantage of:}

- Convenient online submission

- Thorough peer review

- No space constraints or color figure charges

- Immediate publication on acceptance

- Inclusion in PubMed, CAS, Scopus and Google Scholar

- Research which is freely available for redistribution 